thuật trung bình là 45,5 47 phút, thời gian hậu

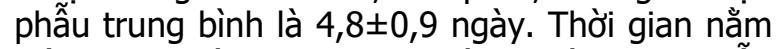
viện trung bình $5,0 \pm 0,9$ ngày. Thời gian phẫu thuật của chúng tôi cao hơn nghiên cứu của Trân Ngọc Lương [6] là 40 phút.

Biến chứng sau mổ. Trong nghiên cứu của chúng tôi có $3 \%$ bệnh nhân bị khàn tiếng tạm thời sau mổ. Ngoài ra có 1 bệnh nhân xuất hiện nuốt vướng sau mổ. 12,1\% bệnh nhân xuất hiện tê bì, giảm cảm giác da vùng cổ. Kết quả phẩu thuật tốt ở 94\% trường hợp, 97\% bệnh nhân hài lòng về kết quả thẩm mỹ sau mổ. Kết quả này cũng tương tự với các nghiên cứu trước đó của Trân Ngọc Lướng [6], Nguyễn Xuân Hậu [7].

\section{KẾT LUẬN}

Phẫu thuật nội soi đường nách vú trong điều trị u tuyến giáp lành tính tương đối an toàn, tỷ lệ tai biến, biến chứng thấp và đạt thẩm mỹ cao.

\section{TÀI LIỆU THAM KHẢO}

1. Lê Văn Quảng (2002). "Nhân xét đăc điểm lâm sàng và các phương pháp điểu trị ung thư tuyến giáp tại Bệnh viện K tứ năm 1992 - 2000". Tạp chí Y học, số (431), 323 - 326.
2. Nguyễn Quốc Bảo (2010). Ung thư tuyến giáp. Điểu trị phâuu thuật bệnh ung thư 2010. Nhà xuất bản y hoc, trang 92-113.

3. Bae, Gia Seong MD; Cho, Young Up MD, Sung, Gi Young MD et al (2008). The current status of endoscopic Thyroidectomy in Korea. Surgical laparoscopy, endoscopy and percutaneous techniques: June 2008-Volume 18- Issue 3-pp231-235.

4. Trân Ngọc Lương, Trân Đoàn Kết, Ta Văn Bình (2004). Phẩu thuât tuyến giáp bẳng kỹ thuật nội soi: một số nhận xét về kỹ thuật và chỉ định mổ. Tạp chí y học thực hành số 491/2004, trang 366-373.

5. Đinh Xuân Cường (2004). "Nghiên cứu đặc điểm lâm sàng, mô bênh học và kết quả điều trị phẫu thuật ung thư tuyến giáp tại bệnh viện $\mathrm{K}^{\prime \prime}$. Luân văn thạc sĩ y học, Hà Nối, $33-48$.

6. Trầ̆n Ngoc Lương (2011). Đánh giá kết quả phẩu thuậ̣t nội soi điêu trị bướu giáp lành tính. Tạp chí phẫu thuất nội soi và nội soi Việt Nam - tập 1 năm 2011, sổ 2 trang 20-24.

7. Nguyen X.H., Nguyen X.H., Mai T.K.N. và cộng sự. (2019). Feasibility and Safety of Endoscopic Thyroidectomy Via a Unilateral Axillobreast Approach for Unilateral Benign Thyroid Tumor in Vietnam. Surg Laparosc Endosc Percutan Tech, 29(6), 447-450.

\title{
ĐÁNH GIÁ KẾT QUẢ HÓA TRI PHÁC ĐỒ Có PEMETREXED TRONG UNG THƯ PHỔI KHÔNG TẾ BÀO NHỎ GIAI ĐOẠN IIIB-IV TẠI BỆNH VIỆN BẠCH MAI
}

\section{TÓM TẮT}

Mục tiêu: Đánh giá kết quả hóa trị phác đồ có Pemetrexed ở bệnh nhân ung phổi không tế bào nhỏ giai đoạn IIIB-IV tại Bệnh viện Bach Mai. Đối tượng và phương pháp nghiên cứu: Nighiên cứu mô tả hồi cứu kết hợp tiến cứu trên 63 bênh nhân ung thư biểu mô tuyến của phổi giai đoạn IIIBB-IV được điều trị hóa chất phác đồ có pemetrexed tại Bệnh viển Bạch Mai từ tháng 6/2018 đến tháng 6/2021. Kết quả: Tuổi trung bình: $61,5 \pm 7,2$; tuổi lớn nhất: 74 ; Tỷ lệ nam/nữ: $1,75 / 1 ; 76,3 \%$ bệnh nhân đạt được đáp ứng cơ năng; trong đó có $16,9 \%$ đáp ứng hoàn toàn; Đáp ứng thực thể: $38,1 \%$ đáp ứng một phân, $39,1 \%$ bệnh ổn định, 20,6\% bệnh tiến triển và có 1 bệnh nhân đáp ứng hoàn toàn; Trung vị thời gian sống không bênh tiến triển là 8,2 tháng (CI 95\%: 7,1-9,5); trung vị thời gian sống thêm toàn bộ là 16,0 tháng; (CI 95\%: 14,2 -

*Trung tâm Y học hạt nhân và Ung bướu, Bệnh viện Bach Mai

Chịu trách nhiệm chính: Lê Viết Nam

Email: vietnamhmu@gmail.com

Ngày nhận bài: 18.6.2021

Ngày phản biên khoa hoc: 17.8 .2021

Ngày duyệt bài: 24.8.2021

\section{Lê Viết Nam*, Phạm Cẩm Phương*}

17,8); Tình trang toàn thân theo ECOG tốt cải thiện tỷ lệ đáp ứng, kéo dài thời gian sống thêm không bệnh tiến triển và thời gian sống thêm toàn bộ. Kết luận: Điều tri ung thư phổi loai biểu mô tuyển giai đoạn IIIB-IV bằng phác đồ hóa chất có pemetrexed giúp cải thiện tỷ lệ đáp ứng và thời gian sông thêm. nhỏ

Tư khóa: Pemetrexed, ung thư phổi không tế bào

\section{SUMMARY}

\section{EVALUATING THE RESULTS OF CHEMOTHERAPY WITH PEMETREXED REGIME IN STAGE IIIB-IV NON-SMALL CELL LUNG CANCER AT BACH MAI HOSPITAL}

Objective: To evaluate the results of chemotherapy with pemetrexed in stage IIIB-IV nonsmall cell lung cancer at Bach Mai Hospital. Subjects and Methods: $A$ retrospective and prospective descriptive study on 63 adenocarcinoma lung cancer patients with stage IIIB-IV who received chemotherapy with pemetrexed at Bach Mai Hospital since June 2018 to June 2021. Results: Mean age: $61.5 \pm 7.2$; the oldest patient: 74 ; male/female ratio: $1.75 / 1 ; 76,3 \%$ of patients achieve clinical symptoms response; of which $16,9 \%$ respond completely; Ratio 
response: $38.1 \%$ partial response, $39.1 \%$ stable disease, $20.6 \%$ progressive disease and 1 patient complete response; Median progression-free survival was 8.2 months (CI 95\%: 7.1-9.5); median overall survival was 16,0 months; (CI 95\%: 14.2 17.8); Good performance status (ECOG) improves response rates, prolongs progression-free survival and overall survival. Conclusion: Treatment of stage IIIB-IV adenocarcinoma lung cancer with chemotherapy with pemetrexed improves response rate and survival time.

Keyword: pemetrexed, non-small cell lung cancer.

\section{I. ĐĂT VẤN ĐỀ}

Ung thư phổi (UTP) là loại ung thư phổ biến và là nguyên nhân gây tử vong do ung thư thường gặp nhất. Theo GLOBOCAN 2020, năm 2020 có 2.206.771 người mắc mới (chiếm $11,4 \%$ ) và 1.796 .144 người tử vong do ung thư phổi (chiếm 18\%) [1]. Mặc dù đã có nhiều tiến bộ trong chẩn đoán và điểu trị nhưng tỷ lệ sống thêm 5 năm với bệnh nhân ung thư phổi chỉ chiếm 4-17\% tùy theo giai đoạn và sự khác biệt khu vực. Tại Việt Nam, tỷ lệ tử vong hàng năm do UTP là 23.797 ca chiếm 19,4\% số ca tứ vong do ung thư nói chung [1]. Triệu chứng sớm của UTP rất nghèo nàn và ít đặc hiệu, khi có biểu hiện lâm sàng thì đa số bệnh đã ở giai đoạn muộn không còn khả năng điều trị triệt căn. Cho đến nay, mặc dù đã có nhiều tiến bộ trong điều trị nhóm bệnh nhân này nhưng hóa chất vẫn đóng vai trò quan trọng trong điêu trị UTP, đặc biệt ở những bệnh nhân không biết hoặc có tình trạng đột biến gen EGFR âm tính, ALK âm tính, ROS 1 âm tính và PD-L1 âm tính. Hóa trị với bộ đôi có platunim kết hợp với 1 một tác nhân thể hệ thứ 3 (pemetrexed, docetacel, gemcitabine, vinorenbine) được coi là phác đồ tiêu chuẩn [2]. Pemetrexed là một thuốc kháng folate thế hệ sau, có hiệu lực mạnh hơn và hoạt tính chống khối u mạnh hơn 5-FU, metrotrexate hoặc raltitrexed. Tại Bệnh viện Bạch Mai, chưa có nhiều nghiên cứu đánh giá về kết quả cũng như mức độ an toàn của phác đồ có pemetrexed trong điều trị bước 1 ung thư phổi loại biểu mô tuyến giai đoạn muộn. Vì vậy, chúng tôi tiến hành làm đề tài này nhằm mục tiêu: Đánh giá kêt quả hóa trị phác đồ có Pemetrexed ở bệnh nhân ung phổi không tế bào nhỏ giai đoạn IIIBIV tại Bệnh viện Bạch Mai.

\section{II. ĐỐI TƯợNG VÀ PHƯƠNG PHÁP NGHIÊN CỨU}

Nghiên cứu mô tả hồi cứu kết hợp tiến cứu trên 63 bệnh nhân được chẩn đoán là ung thư biểu mô tuyến của phổi giai đoạn IIIB-IV được điều trị hóa chất phác đồ có Pemetrexed tại Trung tâm Y học hạt nhân \& Ung bướu Bệnh viện Bạch
Mai từ tháng 6/2018 đến tháng 6/2021.

Tiêu chuân lựa chọn: - Chẩn đoán ung thư phổi không tế bào nhỏ giai đoạn IIIB-IV (Theo phân loại của AJCC năm 2017) [3].

- Có kết quả mô bệnh học là ung thư phổi loại biểu mô tuyến

- Không có đột biến gen EGFR, ALK, ROS 1, BRAF hoặc không biết hoặc dương tính nhưng bênh nhân từ chối điều trị đích

- Chỉ số toàn trang (PS: Performance Status) $\leq 2$

- Có các tổn thương đích để có thể đánh giá đáp ứng theo tiêu chuẩn RECIST

- Chức năng tủy xương, gan, thận trong giới hạn bình thường

- Không mắc các bệnh cấp tính, mạn tính trầm trọng trong thời gian gần

- Điều trị tối thiểu 3 đợt hóa chất có pemetrexed

\section{Tiêu chuấn loại trừ}

- Bệnh nhân chẩn đoán ung thư biểu mô tế bào vảy, ung thư biểu mô tế bào nhỏ.

- Dị ứng với các thuốc điêu trị: pemetrexed, carboplatin, cisplatin

- Mắc các bệnh lý cấp tính trầm trọng đe dọa tính mạng

Các bước tiến hành nghiên cứu:

- Thu nhân các bệnh nhân đủ tiêu chuẩn lựa chọn và loại trừ tham gia nghiên cứu

- Thu thập các thông tin lâm sàng, cận lâm sàng trước điêu trị: Tuổi, giới, Tiền sử hút thuốc lá, thuốc lào, lí do vào viện, các triệu chứng lâm sàng, chỉ số toàn trạng theo ECOG, đặc điểm về khối u nguyên phát, hạch vùng, di căn, các chất chỉ điểm khối u: CEA, Cyfra 21-1 trong huyết thanh.

- Tiến hành điều trị hóa chất một trong hai loai phác đồ: Phác đồ pemetrexed-carboplatin: Pemetrexed $500 \mathrm{mg} / \mathrm{m}^{2}$ da truyên tĩnh mạch ngày 1 ; Carboplatin AUC $=5$ truyền tĩnh mạch ngày 1 ; Chu kỳ 21 ngày.

Phác đồ pemetrexed - cisplatin: Pemetrexed $500 \mathrm{mg} / \mathrm{m}^{2}$ da truyền tĩnh mạch ngày 1 ; Cisplatin $75 \mathrm{mg} / \mathrm{m}^{2}$ da truyền tĩnh mạch ngày 1 ; Chu kỳ 21 ngày.

- Đánh giá kết quả điều trị sau 3 đợt và 6 đợt điều trj:

+ Đáp ứng cơ năng: đánh giá theo tiêu chuẩn của WHO.

+ Đáp ứng thực thể: đánh giá theo tiêu chuẩn RECIST 1.1

+ Đánh giá thời gian sống thêm: thời gian sống không bệnh tiến triển, thời gian sống thêm toàn bộ

+ Đánh giá tác dụng không mong muốn của phác đồ theo tiêu chuẩn đánh giá độc tính 
CTCAE 5.0

- Phân tích và xử lý số liệu bằng phân mềm SPSS 20.0

\section{KẾT QUẢ NGHIÊN CỨU VÀ BÀN LUÂNN}

3.1. Đặc điểm đối tượng nghiên cứu

Bảng 1: Đặc điểm bểnh nhân nghiên cứu

\begin{tabular}{|c|c|c|}
\hline $\begin{array}{c}\text { Đặc điếm bệ̂nh nhân } \\
(\mathrm{n}=63)\end{array}$ & $\begin{array}{c}\text { Số bệnh } \\
\text { nhẩn }\end{array}$ & $\begin{array}{c}\text { Tỉ lệ } \\
(\%)\end{array}$ \\
\hline
\end{tabular}

\begin{tabular}{|c|c|c|c|}
\hline Tuổi & \multicolumn{3}{|c|}{$\begin{array}{c}\text { Trung bình: } 61,5 \pm 7,2 ; \text { lớn nhất: } \\
74 ; \text { thấp nhất: } 47\end{array}$} \\
\hline \multirow{2}{*}{ Giới } & Nam & 40 & 63,5 \\
\hline & Nữ & 23 & 36,5 \\
\hline \multirow{2}{*}{ Hút thuốc } & Có & 30 & 47,6 \\
\hline & Không & 33 & 52,4 \\
\hline \multirow{3}{*}{$\begin{array}{l}\text { Điểm } \\
\text { ECOG }\end{array}$} & 0 & 23 & 36,5 \\
\hline & 1 & 31 & 49,2 \\
\hline & 2 & 9 & 14,3 \\
\hline \multirow{3}{*}{$\begin{array}{l}\text { Số chu kỳ } \\
\text { hóa chất }\end{array}$} & 3 & 1 & 1,6 \\
\hline & 4 & 18 & 28,6 \\
\hline & 6 & 44 & 69,8 \\
\hline \multirow{2}{*}{$\begin{array}{c}\text { CEA } \\
(\mathrm{ng} / \mathrm{ml})\end{array}$} & $\leq 5,0 \mathrm{ng} / \mathrm{ml}$ & 21 & 33,3 \\
\hline & $>5,0 \mathrm{ng} / \mathrm{ml}$ & 42 & 66,7 \\
\hline
\end{tabular}

Nhân xét: Tuổi trung bình 61,5 ; tỷ lệ nam/nữ: 1,75/1; Đa số bệnh nhân có thể trạng tốt: ECOG $\leq 1 \quad(85,7 \%) ; 66,7 \%$ bệnh nhân có tăng CEA huyết thanh

\section{2. Đánh giá đáp ứng cơ năng}

\section{Bảng 3: Đánh giá đáp ứng thực thể với một số yêu tố liên quan}

\begin{tabular}{|c|c|c|c|c|c|c|c|c|c|}
\hline \multirow[t]{2}{*}{  } & & \multicolumn{2}{|c|}{ Đáp ứng } & \multicolumn{2}{|c|}{ Bệnh ốn định } & \multicolumn{2}{|c|}{ Bệnh tiến tiến } & \multirow{2}{*}{$\begin{array}{c}\text { Tống } \\
\text { (n) }\end{array}$} & \multirow[b]{2}{*}{$\mathbf{p}$} \\
\hline & & $\mathbf{n}$ & $\%$ & $n$ & $\%$ & $\mathrm{n}$ & $\%$ & & \\
\hline \multirow{2}{*}{ Giới tính } & Nam & 18 & 45,0 & 14 & 35,0 & 8 & 20,0 & 40 & \multirow{2}{*}{0,495} \\
\hline & Nữ & 7 & 30,4 & 11 & 47,8 & 5 & 21,8 & 23 & \\
\hline \multirow{3}{*}{ ECOG } & 0 & 15 & 65,2 & 8 & 34,8 & 0 & 0 & 23 & \multirow{3}{*}{0,001} \\
\hline & 1 & 8 & 25,8 & 16 & 51,6 & 7 & 22,6 & 31 & \\
\hline & 2 & 2 & 22,2 & 1 & 11,1 & 6 & 66,7 & 9 & \\
\hline \multirow{2}{*}{ Tuổi } & $<60$ tuối & 10 & 34,5 & 12 & 41,4 & 7 & 24,1 & 29 & \multirow[b]{2}{*}{0,696} \\
\hline & $>60$ tuối & 15 & 44,1 & 13 & 38,2 & 6 & 17,7 & 34 & \\
\hline
\end{tabular}

Nhận xét: Tỷ lệ đáp ứng của nam cao hơn ở nữ (45,0\% so với 30,4\%), tuy nhiên sự khác biệt không có ý nghĩa thống kê $(\mathrm{p}=0,495)$

Bệnh nhân có chỉ số toàn trạng tốt có tỷ lệ đáp ứng cao hơn, với điểm chỉ số toàn trạng ECOG $0,1,2$ tương ứng là: $65,2 \% ; 25,8 \% ; 22,2 \%(p<0,001)$

Không có sự khác biệt về tỳ lệ đáp ứng khách quan theo tuổi bệnh nhân.

3.4. Thời gian sống thêm không bệnh tiến triển, sống còn toàn bộ
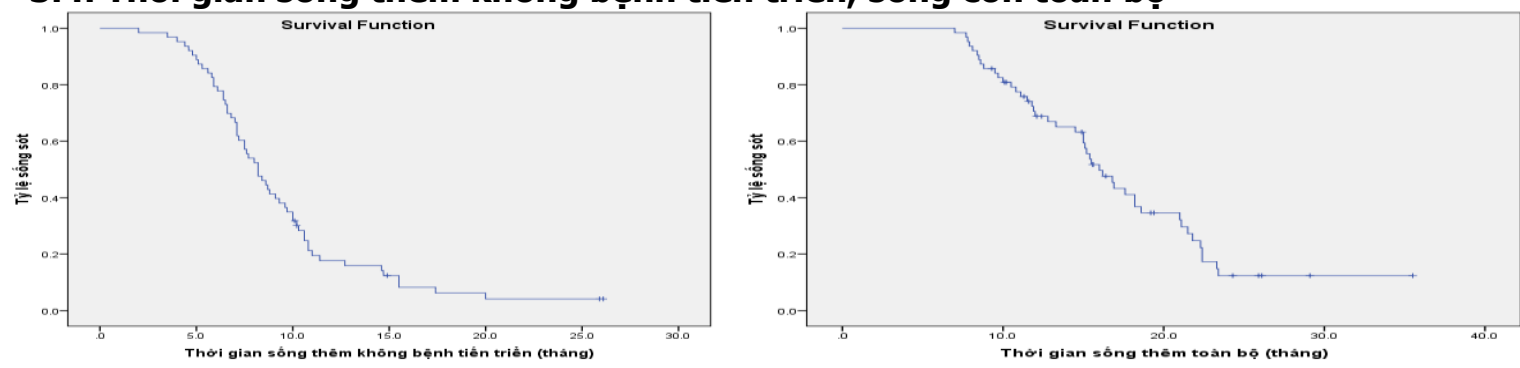

Biểu đồ 2: Thời gian sông thêm 


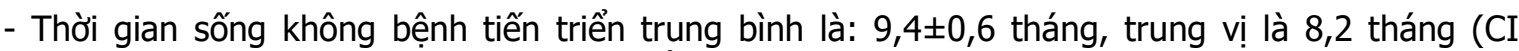
95\%: 7,1-9,5). Tỷ lệ sống không bệnh tiến triển sau 6 tháng là: 77,8\%; sau 12 tháng là: 17,7\%

- Thời gian sống thêm toàn bộ trung bình: $17,8 \pm 1,1$ tháng; trung vị là 16,0 tháng; (CI 95\%: 14,2 - 17,8). Tỷ lệ sống còn sau 12 tháng là $68,8 \%$; sau 24 tháng là 12,4\%.

\subsubsection{Thời gian sống thêm theo tình trạng toàn thân}
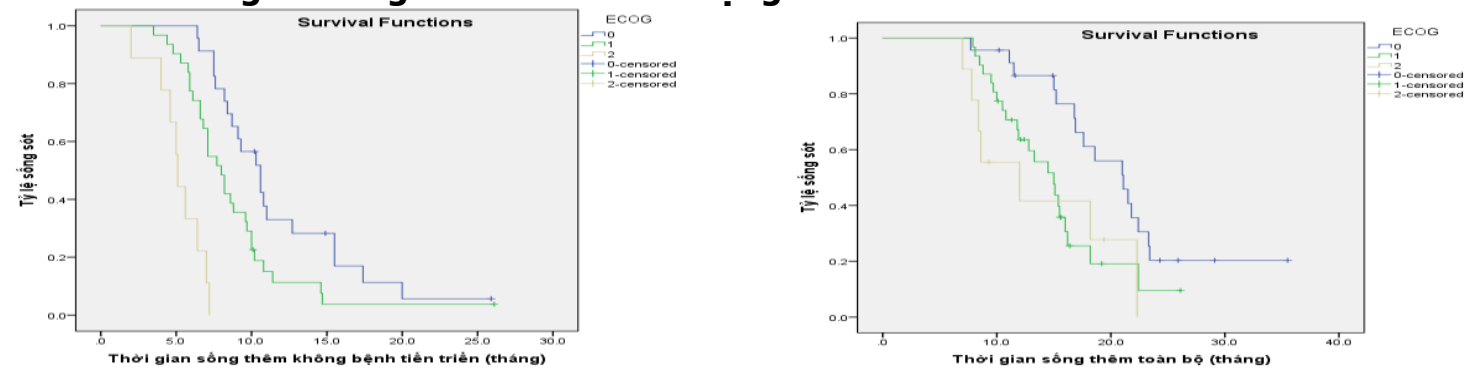

Biểu đồ 3: Thời gian sông thêm theo chỉ số toàn trạng

Cả thời gian sống không bệnh tiến triển và sống thêm toàn bộ ở nhóm thể trạng tốt (ECOG $\leq 1)$ cao hơn ở nhóm thể trạng kém có ý nghĩa thống kê với $p<0,05$

3.4.2. Thời gian sống thêm theo nồng độ CEA trước điều trị
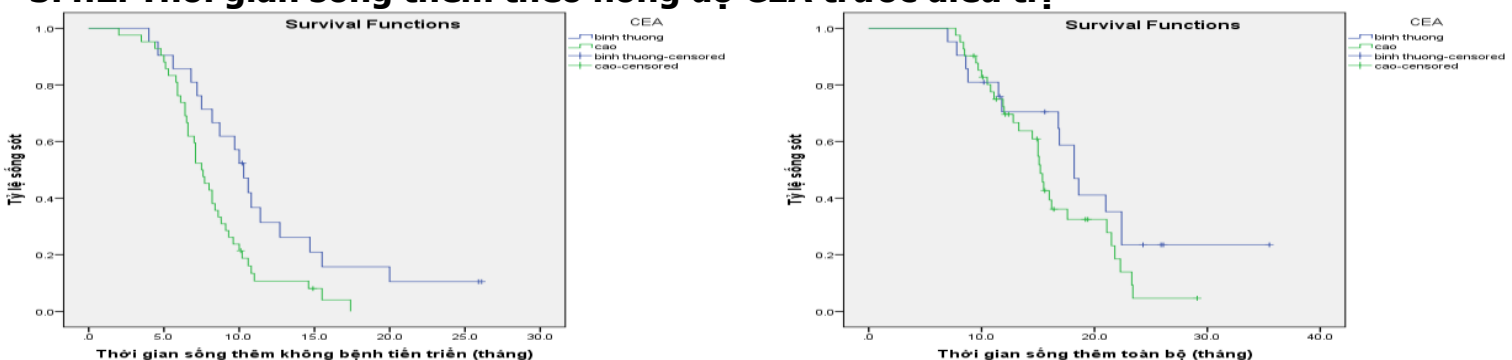

Biêu đồ 4: Thời gian sống thêm theo nồng độ CEA trước điều trị

Thời gian sống thêm không bệnh tiến triển ở nhóm CEA bình thường là 11,7 tháng cao hơn ở nhóm có CEA tăng là 8,2 tháng $(p<0,001)$

Thời gian sống thêm toàn bộ ở nhóm CEA bình thường cao hơn ở nhóm có CEA tăng (20,2 so với 16,2 tháng), tuy nhiên khác biệt không có ý nghĩa thống kê với $p=0,126$

\subsubsection{Thời gian sống thểm theo tình trạng đáp ứng}


Biểu đồ 5: Thời gian sống thêm theo tình trạng đáp ứng

Thời gian sống thêm không bệnh tiến triển ở nhóm bệnh nhân đạt được đáp ứng thực thể cao hơn ở nhóm không đáp ứng (11,4 tháng so với 8,0 tháng) với $p=0,022$

Thời gian sống thêm toàn bộ cũng cao hơn ở nhóm đạt được đáp ứng thực thể (21,6 so với 14,6 tháng) với $p=0,002$.

\section{BÀN LUÂ̂N}

Bệnh nhẩn ung thư phổi giai đoạn muộn đa số có biểu hiện lâm sàng: đau ngực, ho, khó thở, triêu chứng cơ quan di căn... ảnh hưởng đến chất lượng cuộc sống và kết quả điều trị. Mục tiêu điều trị ung thư phổi giai đoan muộn nhằm cải thiện triệu chứng, nâng cao chất lượng cuộc sống và kéo dài thời gian sống thêm. Trong nghiên cứu của chúng tôi có $76,3 \%$ bệnh nhân thuyên giảm triệu chứng lâm sàng, trong đó có 
16,9\% bệnh nhân hết hoàn toàn các triệu chứng. Một số tác giả cũng đã nghiên cứu tỷ lệ cải thiện triệu chứng cơ năng ở bệnh nhân ung thư phổi giai đoạn muộn. Theo Trương Văn Sáng (2019), tỷ lệ đáp ứng cơ năng là 71,1\% [4]. Nghiên cứu Đinh Ngọc Việt (2014), điều trị phác đồ Docetaxel- Carboplatin cho tỷ lệ đáp ứng cơ năng là $66 \%$ [5].

Trong nghiên cứu của chúng tôi, tỷ lệ kiểm soát bệnh đạt 79,4\% trong đó có 1 trường hợp đạt được đáp ứng hoàn toàn, $38,1 \%$ đạt đáp ứng một phần, 39,1\% đạt ổn định bệnh. Tỷ lệ đáp ứng trong một số nghiên cứu trong nước như Trương Văn Sáng (2019) khi điều trị Pemetrexed-carboplatin là 32,2\%; Nguyễn Trọng Hiếu (2012), điều trị phác đồ nab-Paclitaxel carboplatin đối với bệnh nhân ung thư phổi không tế bào nhỏ cho tỷ lệ đáp ứng là 40,9\% [4]. Nghiên cứu của Masaru Ito, Nobuyuki Horita và cộng sự (2018) trên 285 bệnh nhân cho tỷ lệ đáp ứng toàn bộ là 34,0\% (CI 95\%, 27,5-40,5) [6]. Scagliotti và cộng sự (2005) khi so sánh kết quả điêu trị của Pemetrexed phối hợp lần lượt với Oxaliplatin và Carboplatin đã cho tỷ lệ đáp ứng tương xứng là $26, \%$ và $31,6 \%$ [7]. Metro $\mathrm{G}$, Chiari R (2011) nghiên cứu 80 bệnh nhân cho tỷ lệ đáp ứng toàn bộ $42,5 \%$, tỷ lệ kiểm soát bệnh là $77,5 \%$ [8].

Hầu hết các bệnh nhân trong nghiên cứu đạt được kiểm soát bệnh (đáp ứng toàn bộ và bệnh ổn định) đều được điều trị duy trì tiếp theo (duy trì liên tục hoặc duy trì chuyển đổi). Trung vị thời gian sống thêm không bệnh tiến triển trong nghiên cứu của chúng tôi là 8,2 tháng (dao động từ 7,1 - 9,5 tháng), tỷ lệ sống thêm sau 6 tháng, 12 tháng lần lượt là $77,8 \%$ và $17,7 \%$. Nghiên cứu của Trương Văn Sáng (2019) thời gian sống thêm không bệnh là 5,8 tháng, nghiên cứu của Lã Duy Tuyến (2019) là 7,8 tháng [4]. Nghiên cứu Hàn Thị Thanh Bình (2018) sử dụng phác đồ Paclitacel-carboplatin, thời gian sống thêm không bệnh tiến triển là 7,05 tháng [9]. Trong nghiên cúu của Metro G, Chiari R (2011) là 5,8 tháng [8], nghiên cứu của Zinner và CS (2009) là 7,3 tháng [10].

Có rất nhiều tiến bộ trong điều trị bước sau như điều trị miễn dịch đã cải thiện đáng kể thời gian sống thêm toàn bộ ung thư phổi không tế bào nhỏ giai đoạn muộn. Tại thời điểm kết thúc nghiên cứu, có 45 bệnh nhân tử vong. Thời gian sống thêm toàn bộ trong nghiên cứu của chúng tôi trung bình: $17,8 \pm 1,1$ tháng; trung vị là 16,0 tháng; (CI 95\%: 14,2 - 17,8). Tỷ lệ sống còn sau 12 tháng là $68,8 \%$; sau 24 tháng là $12,4 \%$. Thời gian sống thêm toàn bộ trong nghiên cứu của Trương Văn Sáng là 14,0 tháng, nghiên cứu Lã Duy Tuyến là 16,8 tháng [4]. Nghiên cứu của Karayama và cộng sự (2013) điều trị phác đồ pemetrexed-cisplatin sau đó duy trì bằng pemetrexed có thời gian sống thêm toàn bộ là 25,0 tháng.

Nghiên cứu của chúng tôi cho thấy tình trạng đáp ứng và thể trạng bệnh nhân theo điểm ECOG giúp cải thiên thời gian sống thêm (cả PFS và $O S$ ). Một số yếu tố không ảnh hưởng đến thời gian sống thêm toàn bộ như tuổi, giới, nồng độ CEA trước điều trị. Kết quả này cũng tương tự như các nghiên cứu khác trong và ngoài nước.

\section{KẾT LUẬN}

Điều trị ung thư phổi loại biểu mô tuyến giai đoạn IIIB-IV bằng phác đồ hóa chất có pemetrexed giúp cải thiện tỷ lệ đáp ứng và thời gian sống thêm.

\section{TÀI LIỆU THAM KHẢO}

1. Sung $H$, Ferlay $J$, Siegel $R L$, Laversanne $M$ Soerjomataram I, Jemal A, Bray F. Global Cancer Statistics 2020: GLOBOCAN Estimates of Incidence and Mortality Worldwide for 36 Cancers in 185 Countries. CA Cancer J Clin. 2021 May;71(3):209-249. doi: 10.3322/caac.21660. Epub 2021 Feb 4. PMID: 33538338.

2. Joshi A., Noronha V., Patil V.M. et al. (2017). Efficacy of Second Line Pemetrexed - carboplatin in the treatment of metastasis nonsmall cell lung cancer. Chemother Res Pract.

3. Lung Cancer TNM 8th edition. www.ncen.org/ physician_gls/nscl.pdf

4. Trương Vằn Sáng (2019). Đánh giá kết quả điều trị phác đồ pemetrexed - carboplatin trên bệnh nhân ung thư biểu mô tuyến của phổi giai đoan IV. Luận văn thạc sĩ y học. Trường Đại Học Y Hà Nội.

5. Đinh Ngoc Viêt (2014). Đánh giá kết quả điều trị ung thư phổi không tế bào nhỏ giai đoạn IV bắng phác đô docetaxel và carboplatin, Luận văn thạc sỹ y học, Đại học Y Hà Nội

6. Ito M., Horita N., Nagashima A. et al. (2018). Carboplatin plus pemetrexed for the elderly incurable chemo-naive nonsquamous non small cell lung cancer: Meta analysis. Asia Pac J Clin Oncol

7. Scagliotti G.V. (2005). Pemetrexed plus carboplatin or oxaliplatin in advanced non small cell lung cancer. Semin Oncol, 32(2 Suppl 2), S5-8

8. Metro G., Chiari R., Mare M.et al. (2011). Carboplatin plus pemetrexed for platinum pretreated, advanced non-small cell lung cancer: a retrospective study with pharmacogenetic evaluation. Cancer Chemother Pharmacol, 68(6), 1405-1412.

9. Hàn Thị Thanh Bình (2018). Nghiên cứu điều trị ung thư phổi không tế bào nhỏ giai đoạn IIB,IV bằng hóa trị phác đồ cisplatin kết hợp với paclitaxel hoặc etoposide. Luận án tiến sĩ y học. Trường Đại học Y Hà Nội

10. Zinner R.G., Fossella F.V., et al. (2005). Phase II study of pemetrexed in combination with carboplatin in the first-line treatment of advanced nonsmall cell lung cancer. Cancer, 104(11), 2449-2456. 